\title{
Un perfil de Foucault: Notas a partir de una lectura arqueológica del archivo foucaulteano
}

\author{
Iván Gabriel Dalmau ${ }^{1}$
}

\section{A modo de introducción ${ }^{2}$}

\begin{abstract}
En retrospectiva, los trabajos publicados aparecen como fotografías, como recortes momentáneos de un proceso [...]. Sin embargo, la lectura de las lecciones del Collège de France provee un antídoto eficiente para esto. En dichas conferencias vemos a Foucault trabajando, volviendo constantemente sobre cuestiones previas, retomándolas y reformulándolas.
\end{abstract}

Wallenstein, Foucault, Biopolitics and Governmentality

En el presente trabajo recuperamos una serie de discusiones abordadas tangencialmente en el marco de nuestra Tesis Doctoral (Dalmau, 2016), realizada en torno a la problematización del saber que el filósofo francés Michel Foucault elaborara en el marco de su genealogía de la biopolítica. En este artículo pondremos el foco en una cuestión que, si bien escapa al eje de dicha investigación, consideramos nodal a la hora de aproximarnos al discurso foucaulteano y, de hecho, ha sido fundamental para el desarrollo de la citada indagación. Nos referimos específicamente a lo que podría denominarse como "un perfil" de la manera foucaulteana de puesta en práctica del trabajo filosófico. En ese sentido, retomando la cita que hemos colocado como epígrafe, nos ocuparemos de revisar el gesto foucaulteano de recuperación y reelaboración de sus trabajos precedentes desde la perspectiva de sus indagaciones en curso, cuestión que se ha tornado palpable tras la publicación de los cursos dictados por el filósofo en el Collège de France (Raffin, 2015). Al mismo tiempo, buscando problematizar la constitución de dicho "perfil filosófico", nos ocuparemos de dar cuenta de la profunda ligazón que articula al mentado gesto foucaulteano con su posicionamiento en torno a la filosofía crítica.

1 Doctor en Ciencias Sociales (FSOC-UBA). Becario Postdoctoral CONICET. Docente de Epistemología de las Ciencias Sociales (Humanidades-UNSAM) y de Introducción al Pensamiento Científico en el Ciclo Básico Común de la Universidad de Buenos Aires (UBA).

2 Hemos privilegiado el trabajo sobre las fuentes primarias y secundarias en idioma original, razón por la cual las traducciones nos corresponden, excepto que se indique lo contrario. 
Por otra parte, desde un punto de vista formal, sería pertinente remarcar que dividiremos al presente escrito en tres parágrafos. En el primero explicitaremos el modo en que nos apropiamos de las herramientas arqueológicas foucaulteanas para la puesta en práctica de nuestra investigación. Tras lo cual, habiendo explicitado las denominadas "cuestiones de método", en los apartados siguientes nos detendremos en una serie de documentos que constituyen el "archivo Foucault" para dar cuenta del mentado perfil que caracterizaría una faceta del modo en que Michel Foucault ha practicado el trabajo filosófico. Específicamente, en el segundo parágrafo nos detendremos en el modo en que el filósofo buscó ubicarse en torno a una de las "posteridades críticas" erigidas alrededor del legado kantiano; luego, en el último apartado, buscaremos dar cuenta del mencionado gesto foucaulteano de recuperación y reelaboración recurrente de las herramientas fraguadas en sus trabajos precedentes desde el prisma de sus trabajos en curso.

\section{Punto de partida: notas para una lectura arqueológica del archivo Foucault}

A lo largo de las líneas que se despliegan a continuación se pretende llevar a cabo una lectura filosófica de carácter problemático de fragmentos de la discursividad foucaulteana, en torno a lo cual se impone la realización de una serie de aclaraciones, puesto que son varias las aristas implicadas. En términos generales, sería pertinente destacar que el abordaje problemático de los trabajos de Michel Foucault se encuentra jalonado por la búsqueda de herramientas que habiliten a la interrogación respecto de nuestro presente y, por lo tanto, no se encuentra alentado por el intento de elaboración de "la lectura", original e irrecusable, que clausuraría todo tipo de discusión, contribuyendo a la desactivación de la potencia crítica de las herramientas filosóficas foucaulteanas. De hecho, sería más que paradójico proponer un abordaje del discurso foucaulteano erigido a partir de una estrategia metodológica análoga a la que el filósofo francés cuestionara en el marco de sus clásicas reflexiones respecto del método arqueológico (Foucault, 1969). Es decir, que partiendo foucaulteanamente de la base de que la noción de "autor" no remite a una "subjetividad psicológica", con sus "intenciones", ni a su presunta inscripción dentro de una determinada "tradición", sino más bien a una función del discurso (Foucault, 1994a), interrogarnos acerca del "sentido de sus textos" sería comportarnos como investigadores de modo similar al retratado por la clásica metáfora del "perro que se muerde la cola".

Por otra parte, en lo que respecta a las referencias de Michel Foucault a otros filósofos u otras corrientes filosóficas, las consideraremos relevantes en función de la economía del discurso foucaulteano y no como un "problema en sí mismo", cual si sus trabajos fueran los de un comentarista. Por lo tanto, no tomaremos las referencias foucaulteanas, explícitas o no, a la fenomenología o a la filosofía de Immanuel Kant, por ejemplo, como si el suyo fuera un trabajo de historia de la filosofía. En contraposición, distinguiremos lo sugerente que dichas referencias resultan para presentar a su propio registro de interrogación frente al análisis respecto de la plausibilidad filológica de las mismas. En cierto modo, podría decirse que revisaremos al discurso foucaulteano de manera análoga a la que el propio Foucault implementara en su abordaje de los trabajos configurados a partir de mediados del siglo XVI que tenían a la crítica de Maquiavelo como punto de partida. Trabajos en torno a los cuales el filósofo francés explicitó que no se preocuparía respecto 
Iván Gabriel Dalmau/ Un perfil de Foucault: Notas a partir de una lectura [...] / 81 de lo ajustado o no de la lectura que hacían de los textos del clásico pensador político florentino, sino del modo en que en dichos discursos se ponía en juego la contraposición entre los "consejos del príncipe" y el ejercicio del gobierno, que era justamente el problema cuya constitución pretendía abordar (Foucault, 2004).

Declinando levemente las precisiones esbozadas en las líneas precedentes, querríamos mencionar que queda por fuera de nuestros objetivos la puesta en discusión de la caracterización de los trabajos foucaulteanos en tanto presuntamente alineados en una "tradición”. En ese sentido, si bien en el próximo apartado nos detendremos en la búsqueda foucaulteana de inscripción de su propio trabajo en una de las posteridades abiertas en torno a la Crítica kantiana, no es a partir del par categorial "autor"-"tradición" que abordaremos la misma.

\title{
Michel Foucault frente a las posteridades de la Crítica
}

\author{
El objetivo de las investigaciones arqueológico-genealógicas \\ de Foucault no es solamente describir problematizaciones histó- \\ ricas, sino además desenmascararlas y desafiarlas por medio del \\ cuestionamiento de la inevitabilidad y necesidad racional de prác- \\ ticas, instituciones, técnicas y funciones que han sido construidas \\ como respuestas suyas. \\ Mascaretti, \\ "Michel Foucault on Problematization, Parrhesia and Critique"
}

Múltiples son los ejes que se podrían tomar en consideración para brindar un perfil de la manera en que Michel Foucault concibió a la práctica filosófica, por lo tanto, este breve parágrafo no parte de un intento de "unilateralización" del problema, sino más bien de un recorte realizado en función de los objetivos previamente explicitados. Someramente, en tanto antesala de la lectura que propondremos a continuación, querríamos detenernos en la primera clase del curso dictado en el Collège de France durante el ciclo lectivo 1982-1983, es decir, la clase del 5 de Enero de 1983 por medio de la que el filósofo francés diera inicio a su curso titulado Le gouvernement de soi et des autres. De más está aclarar que la revisión de los matices y tensiones que podrían encontrarse entre el conjunto de documentos agrupados en torno al nombre de Michel Foucault que se ocupan del problema de la Crítica queda por fuera de los objetivos y las posibilidades del presente trabajo.

En la mentada clase, Foucault se vale de una presentación del modo en que Immanuel Kant respondió a la pregunta Was ist Aufklärung? para inscribir su propia labor en una modulación de la Crítica. En sus propios términos:

Me parece que la elección filosófica a la que nos encontramos confrontados actualmente es ésta. Hay que optar por una filosofía crítica que se presentará como una filosofía analítica de la verdad en general, o por un pensamiento crítico que tomará la forma de una ontología de nosotros mismos, de una ontología de la actualidad. Y es esta forma de filosofía la que, de Hegel a la Escuela de Frankfurt, pasando por Nietzsche, Max 
Weber, etc., ha fundado una forma de reflexión a la cual, desde luego, me vinculo en la medida en que puedo. (Foucault, 2008, p. 22)

Sería pertinente destacar, entonces, que la filosofía foucaulteana no pretende erigirse como una "analítica de la verdad" preocupada por las posibilidades del conocimiento y sus límites infranqueables, sino que más bien se enmarca en el proyecto de dar cuenta de la constitución histórica de focos de experiencia para poder desentrańar ontológico-politicamente la actualidad y problematizar la contingencia y las posibilidades de franqueamiento de lo presuntamente "universal y necesario". Justamente, por foco de experiencia Foucault concibe la articulación entre las formas de saber, las matrices normativas de comportamiento y los modos de existencia virtual para sujetos posibles (Foucault, 2008); imbricación cuyo desmonte constituye el blanco de la problematización respecto de la actualidad, tal como Foucault lo explicitara en sus trabajos. De lo que se trata, entonces, es de una inflexión del gesto crítico, que desanclado de todo viso de universalidad se desliga a su vez de una pretensión fundadora-normativa. En lugar de configurarse como una gnoseología que dé cuenta de las condiciones de posibilidad del conocimiento, normando las formas adecuadas de conocer, y una ética orientada por la búsqueda de imperativos categóricos, que permita normar las formas moralmente buenas de actuar, la crítica foucaulteana opera por medio del cuestionamiento del pretendido carácter necesario de las formas de pensamiento y de los modos de acción de los sujetos en sus relaciones consigo mismos y con los otros.

\title{
Recuperación y reelaboración recurrente Un perfil filosófico que emerge a partir de los documentos
}

\begin{abstract}
Foucault, en un procedimiento que le era propio, no ha cesado hasta el final de su vida de "releer", de resituar y de reinterpretar sus antiguos trabajos a la luz de los últimos, en una suerte de reactualización incesante.
\end{abstract}

Fontana y Bertani, "Situation du Cours" de Foucault Il faut défendre la société

Hemos decidido dar comienzo a este último apartado remitiéndonos brevemente a una serie de señalamientos realizados por Michel Foucault al inicio de sus conferencias dictadas en la Universidad de Vermont en el año 1982 (Foucault, 1994b), en las cuales desarrollará una problematización de las relaciones entre subjetividad, gobierno y verdad en el marco del abordaje de las denominadas técnicas de sí en la cultura y la filosofía greco-romana. Prácticas a las que en el devenir de las clases contrapondrá tanto a las del "examen de sí mismo" desarrolladas en el ámbito del "cristianismo primitivo" como a las formas de producción de la verdad sobre los sujetos propias de las modernas ciencias humanas. Sin más preámbulos, entonces, partiremos de la inclusión del siguiente fragmento con que Foucault busca contextualizar el tópico a abordar en las conferencias dentro el marco de sus investigaciones precedentes:

Mi objetivo, desde hace más de 25 años, ha sido bosquejar una historia de las diferentes maneras por medio de las que los hombres, en nuestra cultura, elaboraron un saber acerca de sí mismos: la economía, la biología, la 
Iván Gabriel Dalmau/ Un perfil de Foucault: Notas a partir de una lectura [...] / 83 psiquiatría, la medicina y la criminología. Lo esencial, no consiste en tomar este saber como criterio, sino analizar esas pretendidas ciencias como "juegos de verdad" que están ligados a las técnicas específicas que los hombres utilizan con el fin de comprender quiénes son. (Foucault, 1994b, p. 784)

Por otro lado, volviendo nuevamente sobre la relación de las investigaciones en curso con sus trabajos previos, planteará que:

He querido hacer una historia de la organización del saber tanto en lo que respecta a la dominación como en lo que concierne al sí mismo. Por ejemplo, no estudié la locura en función de los criterios de las ciencias formales, sino con el fin de mostrar qué tipo de gestión de los individuos, al interior y al exterior de los asilos, había hecho posible este extraño discurso. Llamo "gubernamentalidad" al punto de encuentro entre las técnicas de dominación ejercidas sobre los otros y las técnicas de sí. [...] Puede que haya insistido demasiado sobre las técnicas de dominación y de poder. Me intereso cada vez más en la interacción que se produce entre sí mismo y los otros, y las técnicas de dominación individual, el tipo de acción que un individuo ejerce sobre sí mismo por medio de las técnicas de sí. (Foucault, 1994b, p. 785)

En torno a lo cual, resulta sumamente sugerente el seńalamiento introducido por el reconocido especialista Gary Gutting, quien en el marco de su clásico trabajo sobre la arqueología foucaulteana, enfatizó en los siguientes términos la relevancia de las indagaciones respecto de "la locura" realizadas por Foucault en su Tesis Doctoral:

Con respecto a los trabajos posteriores de Foucault, Historia de la locura posee un fundamental carácter germinal. Sus tópicos críticos y metodológicos fueron llevados adelante por todo lo que Foucault escribió. [...] A través de todos estos desarrollos, [...] Foucault permanece fiel al objetivo fundamental del método arqueológico tal como apareciera por primera vez en Historia de la locura: entender las estructuras que caen por debajo de aquellas elucidadas por las técnicas estándar de la historia del pensamiento. De modo similar, el objetivo crítico preciso de los posteriores trabajos de Foucault cambia de libro a libro [...]. Pero, a través de ellos, el proyecto continúa siendo el de Historia de la locura: usar la historia para cuestionar la auto-comprensión del conocimiento actual de los seres humanos. (Gutting, 1989, pp. 109-110)

Por otra parte, en un clásico artículo publicado ese mismo año, planteó Foucault que:

Las ideas de las que querría hablar aquí no tienen carácter de teoría ni de metodología. [...] Querría decir, primero, cuál ha sido la finalidad de mi trabajo estos últimos veinticinco años. Ésta no ha sido analizar los fenómenos del poder ni sentar las bases para tal análisis. He buscado más bien producir una historia de los diferentes modos de subjetivación del ser humano en nuestra cultura; me he ocupado, desde esta óptica, de tres modos de objetivación que transforman a los seres humanos en sujetos. [...] Por lo tanto, no es el poder, sino el sujeto, lo que constituye el tema general de mis investigaciones. (Foucault, 1994c, pp. 222-223) 
Ahora bien, en tanto que buscamos trazar un perfil del modo de trabajo foucaulteano, la citada referencia de Gutting al método arqueológico nos permite introducir un pequeño desplazamiento dentro del "archivo Foucault", de modo tal de problematizar distintas aristas que configuran a dicho "perfil filosófico". Nos apropiamos aquí de una caracterización que introdujera el pensador francés Maurice Blanchot en su clásico Michel Foucault tel que je l'imagine (Blanchot, 1986), con respecto a la estrategia de que Foucault se vale para definir el enunciado, y que hacemos extensiva a la estrategia implementada por nuestro "autor" para delimitar el análisis arqueológico. En ese sentido, planteamos que tanto la definición del enunciado, como así también de la metodología arqueológica que lo toma por objeto, se constituye en la prosa foucaulteana por medio de una suerte de "teología negativa". De hecho, podría aseverarse que parte de la dificultad que presenta la lectura de dicho libro, así como todo intento de reconstrucción de sus aspectos fundamentales, radica en que resulta difícil despegarse de dicha estrategia argumental puesta en práctica por Foucault. Pareciera casi imposible sustraerse a dicho juego del discurso foucaulteano, ya que se torna muy difícil la posibilidad de reponer qué entender por arqueología o por enunciado sin reproducir la mentada estrategia: "la arqueología no es..., ni esto, ni aquello, ni esto otro", "el enunciado no es tal o cual cosa...".

En cierto modo, podría plantearse que esta forma de argumentación resulta característica de la economía del discurso foucaulteano. Más allá de las nociones mencionadas, y acorde al registro ensayístico del presente artículo, nos permitimos arriesgar la hipótesis de que el recurso a la "teología negativa" es estructurante del conjunto de trabajos articulados en torno al nombre de Michel Foucault, casi como una suerte de contracara de su reticencia frente al planteamiento de teorías de alcance general. Cuestiones que podrían ser remitidas, a su vez, al modo en que Foucault concibió al ejercicio de la Crítica. El recurso a la "teología negativa" podría ser pensado, entonces, como el reverso del mentado gesto foucaulteano de proposición de hipótesis, que luego son retomadas y reelaboradas en el marco del devenir de sus investigaciones. Podría decirse que la "aproximación por oposición" resulta más lábil y, por lo tanto, abierta a reactualizaciones frente al entorpecimiento con respecto a dicho estilo de trabajo que traería aparejado la utilización de precisas y cerradas definiciones "por la positiva".

¿No podría plantearse, acaso, que el modo en que Foucault buscó inscribir su trabajo en una posteridad de la Crítica, su reticencia con respecto a la propuesta de teorías generales y acabadas, su tendencia a la recuperación y reelaboración de sus trabajos previos desde la perspectiva de sus investigaciones en curso, y el recurso a la "teología negativa", constituyen una cadena, una trama en torno a la que podría trazarse su perfil filosófico?

\section{Bibliografía:}

- Blanchot, M. (1986). Michel Foucault tel que je l'imagine. Paris: Fata Morgana.

- Dalmau, I. G. (2016). (BIO)SABER-(BIO)PODER. Reflexiones en torno a la densidad epistemo-ontológico-politica que vertebra a la problematización del saber elaborada por Michel Foucault en el marco de su genealogía de la biopolítica [Tesis de Doctorado]. 
Iván Gabriel Dalmau/ Un perfil de Foucault: Notas a partir de una lectura [...] / 85 Facultad de Ciencias Sociales, Universidad de Buenos Aires: Buenos Aires.

— Fontana, A., Bertani, M. (1997), "Situation du Cours". En Foucault, M., Il faut défendre la société. Cours au Collège de France. 1976-1977. Paris: Gallimard/SEUIL.

— Foucault, M. (1969). L'archéologie du savoir. Paris: Gallimard.

— Foucault, M. (1994a). "Qu'est-ce qu'un auteur ?”. En Dits et écrits I (1954-1969) (pp. 789-821). Paris, Éditions Gallimard.

— Foucault, M. (1994b). "Les techniques de soi". En Dits et écrits IV (1980-1988) (pp. 783-813). Paris: Gallimard.

— Foucault, M. (1994c). "Le sujet et le pouvoir". En Dits et écrits IV (1980-1988) (pp. 222-223). Paris: Gallimard.

- Foucault, M. (2004), Sécurité, Territoire, Population. Cours au Collège de France (1977-1978), Paris: Gallimard/SEUIL.

- Foucault, M. (2008). Le gouvernement de soi et des autres. Cours au Collège de France (1982-1983). Paris: Gallimard.

- Gutting, G. (1989). Michel Foucault's archaeology of scientific reason. Cambridge: Cambridge University Press.

- Mascaretti, G. M. (2014). "Michel Foucault on Problematization, Parrhesia and Critique". Materiali Foucaultiani, 3(5-6).

- Raffin, M. (2015). "La verdad y las formas políticas: la lectura temprana de la tragedia de Edipo en Michel Foucault". Anacronismo e Irrupción. Revista de Teoría y Filosofía Política Clásica y Moderna, 5(8).

- Wallenstein, S.-O. (2013). "Introduction: Foucault, Biopolitics and Governmentality”. En Nilsson, J., Wallenstein, S.-O. (Eds.). Foucault, Biopolitics and Governmentality. Stockholm: Södertörn University The Library. 